\title{
DISCURSO E IDENTIDADE FEMININA: UMA PROPOSTA DE COMPARAÇÃO ENTRE CONTOS E CRÔNICAS DE CLARICE LISPECTOR
}

Anderson Luiz Teixeira PEREIRA ${ }^{1}$

Sílvio Augusto de Oliveira HOLANDA

\begin{abstract}
RESUMO
A dimensão estética do texto artístico de Clarice Lispector, manifestada por meio dos elementos corporificados na obra de arte, permite-nos redimensionar a interpretação de sua obra a uma outra leitura, cujo enfoque incide sobre a dimensão sociocultural. Com base na metodologia dos postulados da Literatura Comparada e dos Estudos Culturais, o presente trabalho visa a comparação entre três contos clariceanos, a saber "Devaneio e embriaguez de uma rapariga", "Preciosidade" e "O búfalo" — os quais compõem a coletânea Laços de família (1960) — e as crônicas escritas por Clarice Lispector enquanto trabalhava como jornalista em colunas femininas, textos esses reunidos em Correio Feminino (2006). A finalidade de analisar dois objetos, cuja diferenciação não se resume a uma simples questão de gênero, é observar como ambos os textos, por mais que trabalhem com o mesmo eixo temático: a figura feminina, eles refletem discursos sobre a identidade feminina e como estão contingenciados ao sujeito da enunciação e ao meio cultural de onde partem. Portanto, é necessário refletir, a partir dos objetos selecionados neste trabalho e os considerando como uma representação de uma cena cultural, sobre a problematização de um discurso que construa ou desconstrua uma identidade feminina normativa na obra da escritora modernista brasileira. Nesse sentido, sua obra manifesta-se, também, como produto de uma microfísica do poder (FOUCAULT, 1979), uma vez que, integrada à dimensão sociocultural, ela permite confrontar ideologias e valores dos laços sociais modernos.
\end{abstract}

Palavras-chave: Clarice Lispector. Literatura comparada. Estudos Culturais.

\begin{abstract}
The aesthetic dimension of the artistic text of Clarice Lispector, manifested in the presents elements in the work of art, give to us the possibility to interpret her work by another reading, one which focus on the sociocultural dimension. Based on the methodology of Comparative Literature and Cultural Studies, the present work aims to do a comparation between three Clariceano tales, entitled "Devaneio e embriaguez de uma rapariga ", "Preciosidade" and "O búfalo" - which compose the tale book Laços de familia (1960) - and the chronicles written by Clarice Lispector while she worked as a journalist in women's columns, texts that are collected in Correio Feminino (2006). The purpose to analyze two objects, whose differentiation is not limited to a simple gender issue, is to observe how both texts, even though they introduce the same thematic axis: the female figure, they reflect discourses about the feminine identity and how they use to be to contingented upon the subject of enunciation and the cultural environment where they come. Therefore, it is necessary to reflect, from the objects selected in this work and considering them as a representation of a cultural scene, on the problematization of a discourse that constructs or don't constructs a feminine normative identity in the work of the Brazilian Modernist writer. In this sense, her work also manifests as a product of a "micorofisica do poder" (FOUCAULT, 1979), since, integrated to the socio-cultural dimension, it allows to confront ideologies and values of modern social ties.
\end{abstract}

Keywords: Clarice Lispector. Comparative Literature. Cultural Studies.

1 Mestrando em Estudos Literários no Programa de Pós-graduação em Letras da Universidade Federal do Pará. E-mail: luizandersson@hotmail.com
2 Doutor em Teoria Literária e professor do Instituto de Letras e Comunicação da Universidade Federal do Pará. E-mail: eellip@hotmail.com.

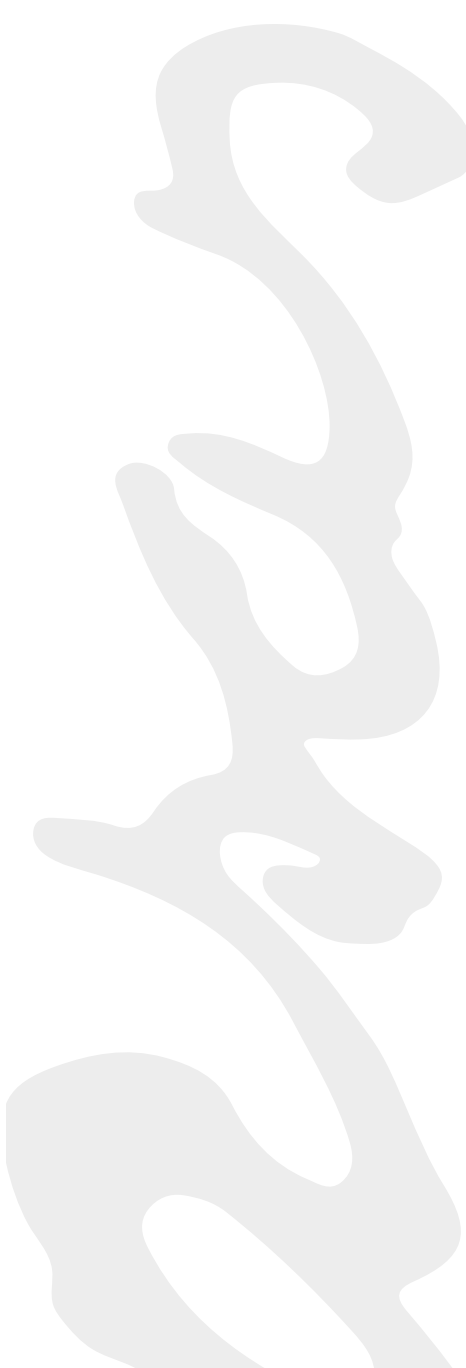




\section{NTRODUÇÃO}

O que há de mais trivial em Clarice Lispector (1920-1977) talvez seja a ponta de um iceberg necessária para pensarmos na dimensão social do seu texto. Nos vários estudos realizados sobre a obra clariceana, já se apontou o predomínio de personagens femininas ocupando o eixo central da narrativa. Resta-nos, portanto, perguntar qual o sentido desse dado e que diferença isso provocaria na interpretação desses textos.

É necessário lembrarmos que a recepção crítica de Clarice Lispector demonstrou a construção de um estilo de escrita intimista, conforme a análise de Alfredo Bosi (2006, p.422) e o desenvolvimento de temáticas marcadamente existenciais, como apontou Benedito Nunes (1989, p. 15) em sua leitura seminal acerca da obra da escritora. Outras vozes se ocuparam no empreendimento de uma leitura baseadas nos procedimentos que caracterizaram sua produção como uma narrativa moderna, seu trabalho com a linguagem, etc.

O que queremos dizer é: existe uma outra dimensão do texto clariceano que, apesar de parecer velada, escondida nas camadas discursivas, é possível entrevê-la por meio de temáticas e representações, as quais permitem perceber o fenômeno do "deslocamento do sujeito" feminino (HALL, 2011, p. 34) na ficção clariceana ao localizarem o espaço social da narrativa como palco da fragmentação da identidade das próprias personagens.

Se considerarmos, por exemplo, a obra-prima de Lispector, A paixão segundo G.H. (1964), notaremos que esse romance, narrado em primeira pessoa, tem como personagem-narrador uma mulher, G.H., cuja identidade é subtraída, pois dela conhecemos apenas as iniciais. Talvez pareça insignificante, contudo, para além da angustia individualizada de G.H. e do desenvolvimento de temáticas existenciais, um questionamento nos faz repensar e redimensionar nossa leitura acerca desse romance: poderia, ao invés de uma mulher, um homem sentir um "arcaico horror por baratas" (LISPECTOR, 2009, p. 46).

Pouco importa estabelecer uma resposta para a essa indagação. A potencialidade do questionamento supramencionado reside na provocação de um problema para o pensamento. É mediante essa inquirição, pois, que tentaremos desenvolver o presente trabalho. Por mais que Clarice Lispector escreva uma narrativa que "mergulha nos veios arqueológicos, em camadas afetivas culturalmente soterradas da sensibilidade humana" (NUNES, 2006, p. 217), indiretamente ou implicitamente, o seu texto situa questões relacionadas à problematização de uma identidade feminina construída por valores sócio-ideológicos tradicionais, fruto de uma estrutura social patriarcal, a qual tende a se reproduzir na pós-modernidade.

Há de se ressaltar que alguns textos clariceanos possuem uma abertura maior para se discutir a temática "discurso e identidade feminina". Por esse motivo, selecionamos a obra literária que, pelo próprio título, já evidencia a questão abordada: Laços de família (1969) - coletânea de contos compostas por treze narrativa, das quais selecionamos apenas três, a saber, "Devaneio e embriaguez de uma rapariga", "Preciosidade" e "O búfalo". Para fomentar nossa discussão e ampliá-la para além dos textos consagrados pela crítica clariceana, selecionamos uma produção de Clarice Lispector que está à margem do cânone literário: as crônicas escritas em páginas femininas. Esses textos, enfeixadas em Correio feminino (2006), assemelham-se aos contos pelo menos em dois aspectos: trata-se de textos enunciados por uma voz feminina, e, segundo, também possuem especificidades contingenciadas pelo local de fala. Tais assertivas, necessariamente, precisarão ser consideradas neste trabalho comparativo.

Portanto, o sustentáculo teórico deste trabalho são os postulados da Literatura Comparada, as teorias pós-coloniais, entre outros. No que se segue, refletiremos sobre os contos e crônicas selecionadas com a finalidade de apontar as similitudes e as divergências entre eles e, por fim, verificar, por meio da configuração narrativa/ textual, o que eles constroem discursivamente sobre o fenômeno, aqui abordado. 


\section{REPRESENTAÇÃO, DISCURSO E IDENTIDADE FEMININA}

Para lembramos o sentido de um trabalho de Literatura Comparada, Henry Remak esclarece-nos que a tarefa dessa disciplina é "dar aos estudiosos, aos professores e estudantes, e, last but not least, aos leitores, uma compreensão melhor e mais completa da literatura como um todo [...]" (REMAK, 1994, p. 180).

Abordar o fenômeno aqui levantado em dois gêneros literários distintos significa uma compreensão maior da questão investigada na obra da escritora Clarice Lispector. Mas não apenas isso. Ao se emparelhar os contos com as crônicas escritas em colunas femininas, é possível ler as singularidades, as quais - salvo o propósito das histórias literárias em dar conta de uma história no sentido singular e continuada — não é descrita pela historiografia de um modo geral. Cabe aos críticos e estudiosos de literatura elaborar uma história não linear, que seja uma série em que se descreva, minunciosamente, as especificidades do trabalho realizado pelo artista.

Nesse sentido, interpretar essas crônicas, as quais estão à margem do cânone da literatura brasileira, é, portanto, sair da zona limítrofe da crítica de Lispector, historicamente legitimada, e adentrar num horizonte maior, no qual se pode construir outras experiências estéticas.

Não há dúvida quanto o lugar ocupado por Clarice Lispector no cânone da literatura brasileira. Para citarmos umas das mais importantes: História concisa da literatura brasileira, de Alfredo Bosi, a autora modernista aparece significativamente. Contudo, outros textos seus, como as suas crônicas escritas para os jornais, sobretudos àquelas escritas em colunas femininas, não aparecem nessa historiografia e nem ao mesmo são citadas. Seria romântico demais propor um lugar para esses textos. É evidente que eles não se ajustam, esteticamente, ao projeto literário de Clarice Lispector e tão pouco ao do modernismo brasileiro. São escritos oriundos de um momento específico da vida da escritora, enunciados num espaço caracteristicamente direcionado para atingir um público particular, conforme Aparecida Maria Nunes:

Clarice tinha consciência de que não podia esquecer o perfil do púbico para quem dava conselhos utilitários e ensinava a refletir sobre cenas domésticas e do universo da mulher. A ficcionista sabia também que tinha de manejar uma linguagem mais despojada e adotar um discurso calcado na estética da imprensa feminina, construída no tom de conversa íntima, afetiva e persuasiva. (NUNES, 2006a, p. 7-8)

Não é difícil de se justificar o fato supracitado. Parece-nos plausível o que escreve a estudiosa citada anteriormente no texto introdutório de Correio Feminino (2006), em que afirma que: "É evidente que esses textos não possuem qualidade literária daqueles que compõem a sua hoje conceituada ficção" (2006).

Mas, se quisermos esgarçar o limite da leitura e propusermos uma análise sobre a representação da figura social da mulher em Clarice Lispector, devemos englobar os textos que constroem discursivamente uma fisionomia de identidade feminina no contexto da sociedade moderna. Nesse sentido, essas crônicas se configuram como, considerando Foucault (2014), arquivos, os quais, potencialmente, são constituídos de vestígios do fenômeno social, que ora investigamos.

Para observar como se configura o "discurso e identidade feminina" na obra clariceana, é necessário, portanto, observar a curva, o diferente, a fronteira: o qual consideramos ser, aqui, as crônicas escritas nas colunas femininas. Interessa-nos revirá-las, questioná-las, estabelecer um jogo dialético com elas, a fim de descrever os seus valores sociais para um exercício reflexivo sobre os discursos que constrói uma identidade feminina tradicionalmente legitimada pelas instituições que detêm o poder

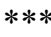


Nos três contos clariceanos selecionados: "Devaneio e embriaguez de uma rapariga", "Preciosidade" e " O búfalo", enfeixados em Laços de família (1960), narra-se, de maneira muito particular e específica em cada um, o conflito de três personagens mulheres, cujos dramas existenciais tendem a se intensificar a medida em que o eixo mimético da narrativa estabelece um nexo com espaço social como o lugar de conflito de suas identidades.

São, portanto, três histórias distintas, mas que se aproximam ao colocarem — para lembrarmos o sentido aristotélico de representação, segundo o qual "a obra do poeta não consiste em contar o que aconteceu, mas sim coisas quais podiam acontecer" (ARISTÓTELES, 2005, p. 28) — a construção da identidade feminina como um dos eixos temáticos representados.

Do ponto de vista do jogo da enunciação, conforme Bakhtin, "O artista utiliza a palavra para trabalhar o mundo, e para tanto a palavra deve ser superada de forma imanente, para tornar-se expressão do mundo dos outros e expressão da relação de um autor com esse mundo." (BAKHTIN, 1997, 209). A assertiva bakhtiniana ajusta-se ao trabalho artístico de Clarice Lispector efetuado nos contos ora analisados. Pode-se entrever, como pano de fundo, uma pauta discursiva que, por meio do trabalho com a linguagem, absorve, refuta e subverte os valores sócio ideológicos da sociedade da segunda metade do século XX, época em que mais ou menos foram escritos esses contos ${ }^{3}$.

Essas narrativas operam uma "linguagem carregada de significados até o máximo grau possível” (POUND, 2006, p. 32). Desse modo, os signos presentes possibilitam e provocam uma leitura que engloba a dimensão sociocultural, no sentido de uma relação intrínseca entre literatura e sociedade, sobre a qual nos esclarece melhor, as palavras do mestre Antonio Candido:

Hoje sabemos que a integridade da obra não permite adotar nenhuma dessas visões dissociadas; e que só a podemos entender fundindo texto e contexto numa interpretação dialeticamente integra, em que tanto o velho ponto de vista que explicava pelos fatores externos, quanto o outro, norteado pela convicção de que a estrutura é virtualmente independente, se combinam como momentos necessários do processo interpretativo. Sabemos, ainda, que o externo (no caso, o social) importa, não como causa, nem como significado, mas como elemento que desempenha um certo papel na constituição da estrutura, tornando-se, portanto, interno. (CANDIDO, 2006, p.13)

3 Alguns dos contos que integram a versão final de Laços de família (1960) foram escritos ainda na década de 1950. Contos como "Amor" e "Os laços de família" já haviam sido publicadas na primeira coletânea de contos de Clarice Lispector,

Alguns contos, em 1952.

4 Conforme Gotlib (2011, p. 340), Clarice Lispector assina a coluna com o pseudônimo "Tereza Quadros", inventado por Rubem Braga, de quem havia vindo o convite para escrever nessa coluna.

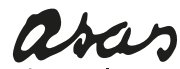

VOL. $14 \mid$ N. 2 da palavra ISSN 1415-7950
Por outro lado, as crônicas — objeto da comparação deste trabalho, enfeixadas em Correio feminino (2006), organizado por Aparecida Maria Nunes - são textos escritos por Clarice Lispector enquanto trabalhava como colaboradora em três colunas femininas de jornais cariocas. A primeira coluna é "Entre mulheres”, do Jornal Comício, na qual escreveu durante o período de 15 de maio a 12 de setembro de 1952, sob o pseudônimo ${ }^{4}$ de Tereza Quadros. Posteriormente, seu trabalho se realiza na coluna "Correio feminino", do jornal Correio da manhã, datado de agosto de 1959 a fevereiro de 1961. Por fim, em "Só para mulheres", sob a égide de ghost writer de Ilka Soares, trabalhou entre abril de 1960 a março de 1961.

O primeiro paralelo possível de ser traçado entre os contos e as crônicas é o fato de que esses textos foram escritos num período relativamente próximo, situado na segunda metade do século XX. De relance, poderíamos afirmar que são textos oriundo de uma mesmo período histórico. Vale lembrar que o século XX é uma época ímpar da história brasileira, sobretudo no que se refere ao campo da literatura. Clarice Lispector havia surgido num momento de grande ebulição intelectual brasileira. Seu romance de estreia, Perto do coração selvagem (1943), causou, por exemplo, em Antonio Candido, um "verdadeiro choque ao ler o romance diferente que é Perto do coração selvagem" (CANDIDO, 1970, p. 127). Daí em diante, a escritura clariceana marcou um novo capítulo da história da literatura brasileira moderna. 
A digressão acima explica-se pela necessidade de falarmos sobre o momento em que a autora começou a escrever para as colunas femininas dos jornais supracitados. À época, escritora já consagrada, amplamente aceita pela crítica literária moderna, tinha receio de ocupar um local de enunciação diferente daquele em que escrevia a maioria de sua narrativa. $O$ espaço nas colunas femininas a restringia à uma escritura específica, com a obrigação de atingir um público outro, diferente daqueles que compunham a recepção de seus textos literários. Daí a necessidade de escrever sob pseudônimo, conforme as cogitações de Gotlib, que nos parece ser bastante pertinente:

Por que o pseudônimo? Talvez Por causa do próprio caráter da matéria. Não era mais a escritora que escrevia os textos, mas "alguém" que, imbuido do espírito jornalístico, se encarregava de tarefas diversificadas - selecionar textos, traduzir alguns, escrever outros, recortar modelos de vestidos, simular conversas com vizinhas, com amigas, com profissionais, de várias especialidades, no sentido de recolher deles conselhos úteis e, finalmente, montar a página com todo esse material. (GOTLIB, 2011, p. 341)

Escrever crônicas, cuja temática principal era retratar aspectos relacionados ao cotidiano da dona de casa da classe média carioca, significou um distanciamento da estética moderna sob o qual a autora produzia seus textos. Desse modo, o local de fala ou de enunciação, por ser atravessado por um conjunto de especificidades, justifica o dinamismo e a composição dessas crônicas.

Outro fator, porém, não menos importante, o qual deve ser considerado, é que esses textos foram produzidos a partir de uma relação de trabalho. Assim, as crônicas tendiam a manter-se dentro dos limites estabelecidos no ato do contrato trabalhista ${ }^{5}$. Entretanto, considerando as proposições acima, há de se deixar de lado o sentido pejorativo de "Colunas femininas", e pôr em evidência que esses textos são produtos de Clarice Lispector, os quais foram poucos estudados e que projetam, por estarem contingenciados à sociedade, uma identidade da mulher tradicional ou normativa.

Emparelhamos as crônicas com os contos já consagrados pela crítica literária, para perceber o que eles dizem, seja em relação a Clarice Lispector enquanto escritora mulher, seja para descrever as marcas registradas de um passado histórico em que se atribuía à mulher apenas o papel de mãe, de dona de casa, de zeladora da moral e dos bons costumes, etc.

A representação da figura da mulher estabelecida nos contos "Devaneio e embriaguez de uma rapariga", "Preciosidade" e "O búfalo" surte o efeito de uma microfísica do poder, no sentido do texto enquanto produto de manifestação contrária às ideologias opressoras. Michel Foucault (1979) atribui ao intelectual o "dever" de expor os discursos suplantados pelas instâncias que detêm esse poder:

Mas existe um sistema de poder que barra, proibe, invalida esse discurso e esse saber. Poder que não se encontra somente nas instâncias superiores da censura, mas que penetra muito profundamente, muito sutilmente em toda a trama da sociedade. Os próprios intelectuais fazem parte desse sistema de poder, a ideia de que eles são agentes da 'consciência' e do discurso também faz parte desse sistema, o papel do intelectual não é mais o de se colocar 'um pouco na frente ou um pouco de lado' para dizer a muda verdade de todos; é antes o de lutar contra as formas de poder exatamente onde ele é, ao mesmo
5 Apesar dessa relação de trabalho, Clarice Lispector desfrutava de certa liberdade para produzir essas páginas. (Ver GOTLIB, 2011) 
tempo, o objeto e o instrumento: na ordem do saber, da 'verdade', da 'consciência', do discurso. (FOUCAULT, 1979, p. 71)

O desenvolvimento narrativo dos três contos supracitados, considerando o contexto maior, no qual estão inseridos, estabelece um nexo com o que escreve Michel Foucault a respeito do intelectual como o porta voz das "verdades". Esses contos podem ser lidos como instrumentos simbólicos de exposição e refutação dos discursos tradicionais que limitam e impõem uma posição social fixa à mulher. Podemos pensar que Clarice Lispector, em sua formação ideológica ${ }^{6}$, preocupava-se em desconstruir esses paradigmas, fato verificável, por exemplo, num texto datada do ano de 1941, escrito enquanto cursava a Faculdade de Direito da Universidade do Brasil:

Tornou-se velho o problema da mulher, embora date apenas da Grande Guerra, tanto foi ele visado e estudado. Deve ou não deve ela estender suas atividades pelos vários setores sociais? Deve, ou não, voltar suas vistas também para fora do lar? De um lado - apresenta-se-nos ela seguindo apenas seu eterno destino biológico, e de outro - a nova mulher, escolhendo livremente seu caminho. (CLARICE, 2000, p. 42)

Em sentido oposto aos contos, as crônicas escritas nas colunas femininas são imbricadas por discursos que manifestam uma ideologia de herança patriarcal. Pensar como a questão da identidade feminina aparecem nesses textos de Clarice Lispector é tarefa importante quando se fala sobre a dimensão sociocultural do texto literário. Judith Butler, ao problematizar as legitimações discursivas que englobam a construção da identidade feminina, elucida-nos que:

Obviamente, a tarefa politica não é recursar a política representacional - como se pudéssemos fazê-lo. As estruturas jurídicas da linguagem e da política constituem o campo contemporâneo do poder. Consequentemente, não há posição fora desse campo, mas somente uma genealogia crítica de suas próprias práticas de legitimação. Assim, o ponto de partida crítico é o presente histórico, como definiu Marx. E a tarefa é justamente formular, no interior dessa estrutura constituida, uma crítica às categorias de identidade que as estruturas jurídicas contemporâneas engendram, naturalizam e imobilizam. (BUTLER, 2003, p. 22)

6 Quando ainda estava na faculdade de direito, Clarice Lispector escreveu um texto intitulado "Observações sobre o direito de punir", no qual discute questões relacionadas a concepção de poder, no sentido dele como manifestação contrária a certas instituições que o detém.
Acordou com o dia atrasado, as batatas por descascar, os miúdos que voltariam à tarde das titias, ai que até me faltei ao respeito!, dia de lavar roupa e serzir as peúgas, ai que vagabunda que me saíste!, censurou-se curiosa e satisfeita, ir às compras, não esquecer o peixe, o dia atrasado, a manhã pressurosa de

sol. (LISPECTOR, 2009, p. 12)
Nesse sentido, os contos clariceanos analisados neste trabalho cumprem o papel de mobilizar a identidade legitimada ao longo da história pelas estruturas de poder. $\mathrm{O}$ trabalho subversivo com a linguagem realizada por Lispector possibilita o "deslocamento" (HALL, 2011, p.24) desse sujeito, no sentido de ele romper com os paradigmas que constroem uma identidade tradicional. Por outro lado, as crônicas — longe de qualquer processo de valoração nosso - refletem, no sentido singular, o modelo de mulher ideal, bem como uma identidade única, a qual não admite desvio. Os trechos abaixo, respectivamente do conto "Devaneio e embriaguez de uma rapariga" e da Crônica "Dirigir um lar", ilustram a questão levantada: 
Somente uma mulher, e dona de casa, sabe reconhecer a grande tarefa que é bem dirigir uma casa. A dona de casa tem de ser, antes de tudo, uma economista, uma 'equilibrista' das finanças, principalmente com as dificuldades da vida atual. $O$ lar é o lugar onde devemos encontrar a nossa paz de espírito num ambiente limpo, sadio e agradável e cabe à mulher providenciar isso. (LISPECTOR, 2006, p. 45)

No conto citado, descreve-se, por meio de um narrador onisciente, um dia qualquer de uma mulher portuguesa. O trecho apesentado acima, espécie de monólogo interior, refere-se ao dia posterior ao que a personagem protagonista da narrativa passara trancafiada em seu quarto, longe dos cuidados domésticos.

Como pano de fundo se observa, primeiramente, a composição de um núcleo familiar tradicional: o marido que saiu para trabalhar, os filhos que estão na casa da tia e por fim, a mulher-mãe responsável por administrar a casa. Contudo, essa mulher encontra-se perturbada, chega a se depreciar — "ai que vagabundo me saístes" —, pois havia transgredido, ao passar um dia inteiro na cama, a sua função de "boa dona de casa".

Mas o sentido imposto a essa trama, esconde, nos vários símbolos que aos poucos emergem na narrativa, uma outra intenção: romper com o discurso suplantado historicamente, os quais construíram uma identidade padrão de mulher.

A rotina dessa dona de casa é quebrada quando, numa noite de sábado, ela saíra acompanhando seu marido num jantar com o chefe. Eis que surge, durante o jantar. a figura metafórica do vinho, que a elevará a um estado de "Embriaguez". A mulher alcançará o êxtase de sua existência, até então coisificada, ao sair do limite em que estava para alcançar um estado de consciência de si por meio da embriaguez, que ultimar-se-á na sua transformação de mulher para "rapariga", lido aqui, não comumente como "mulher", como seria apreendido pelo fato dela ser portuguesa, mas sim, estabelecendo um jogo de polissemia com essa palavra, como "prostituta", sujeito, o qual, historicamente, aparece como a transgressora da moral e dos bons costumes da mulher "tradicional".

A crônica "Dirigir um lar", em sentido oposto, é a lição de uma mulher ficcional, que dar dicas para suas leitoras de como cuidar do marido, dos filhos, da casa, do casamento, etc. Essa temática reforça o discurso sobre o lugar que a mulher deveria na distribuição dos papéis sociais e expõe a identidade normativa da mulher moderna.

Apesar de tanto o conto quanto a crônica orbitarem em torno da temática da relação da mulher com os laços sociais, há uma divergência discursiva entre elas: as crônicas apenas manifestam os discursos que constroem o sujeito mulher em sua constituição arbitrariamente tradicional, ou seja, aquela cuja função é ser adjutora. Os contos, por sua vez, não apenas revelam isso, mas tecem, ainda que seja de maneira velada, críticas a esses discursos.

Embora as crônicas não apresentem a poeticidade e nem o trabalho de elaboração estética como efetuados nos contos, há na sua construção textual enquanto linguagem, o seu maior significado, o qual se revela a partir do estabelecimento de um jogo dialético, isto é, quando os colocamos na condição de arquivos e, como resultado, percebemos evidências de um passado que construía a figura feminina do modo sobre o qual já temos falado.

Em "Preciosidade", por trás do cotidiano de uma mulher adolescente na idade de quinze anos, inserida no ceio de uma família tradicional, há a temática do medo que a mulher sente em relação a potencialidade brutal do homem: "Então subia, séria como uma missionária por causa dos operários no ônibus que 'podiam lhe dizer alguma coisa'. Aqueles homens que não eram mais rapazes. Mas também de rapazes tinha medo, medo também de meninos" (LISPECTOR, 2009, p. 83).

Todos os dias a garota percorria o mesmo itinerário patético: para chegar a escola pegava um ônibus e um bonde e por fim, ainda tinha de atravessar o corredor da escola, onde "os colegas estariam de pé conversando" (LISPECTOR, 2009, p.
7 O trecho final do conto "Devaneio e embriaguez de uma rapariga": " Então, a grosseira implodiu-lhe em súbito amor: Cadela, disse a rir." (LISPECTOR, 2009, p. 18) esboça bem o sentido de rapariga como prostituta, apresentado por nós, pois com descrito na citação acima, a própria personagem, rindo de si, chama-se de cadela. 
84). A temática do medo em relação aos homens desenvolvida neste conto, denota um aspecto do cotidiana de várias mulheres. Historicamente, os discursos sempre apontaram o domínio social e sexual masculino, os colocando como o conquistador. A figura do homem, neste conto, representa, metaforicamente, os perigos que a mulher está exposta no mundo externo, onde a vida acontece: "E então já não se apressou mais. A grande imolação das ruas. Sonsa, atenta, mulher de apache.” (LISPECTOR, 2009, p. 87)

Como é característico dos contos clariceanos, o cotidiano das personagens é interrompido por acontecimento brusco, o qual culmina no clímax da narrativa. A rotina descrita acima é quebrada porque a personagem “ (...) errara os minutos: saíra de casa antes que a estrela e dois homens tivessem tempo de sumir" (LISPECTOR, 2009 , p. 87). Uma força violenta e aterrorizadora a acomete no momento em que, sozinha na rua, avista dois homens. Mas o que se segue, culminará no sacrifício da sua preciosidade, que carregava consigo por ser mulher:

Mas o que aconteceu não teve explicação.
O que se seguiu foram quatro mãos difíceis, foram quatro mãos
que não sabiam o que queriam, quatro mãos erradas de quem
não tinha evocação, quatro mãos que a tocaram tão inespera-
damente que ela fez a coisas mais certa que poderia ter feito no
mundo dos momentos: ficou paralisada. (LISPECTOR, 2009,
p. 90)

O curso da narrativa evidencia a força brutal que as quatro mãos que a tocaram desencadearam na existência daquela mulher. $\mathrm{O}$ próprio discurso narrativo refuta a atitude daqueles homens: "eles não compreenderam a função que tinham e, com a individualidade dos que têm medo, haviam atacado". Ao final da via-crúcis, sacrificaram a sua preciosidade - aquilo "Que era intenso como uma joia. Ela." (LISPECTOR, 2009, p. 82). O assédio dos dois homens agregava a potencialidade de estilhaçar a firmação da personagem enquanto mulher.

O desfecho não poderia ser outro se não o revelado no grito dado por ela algumas horas depois no banheiro da escola: "Estou sozinha no mundo! Nunca ninguém vai me ajudar me ajudar, nunca ninguém vai me amar! Estou sozinha no mundo" (LISPECTOR, 2009, p. 92). O conto esboça a realidade de muitas mulheres que sentem medo, seja pelo que for, mas que perpassa o fato de serem mulheres.

A cena final, durante o jantar com a família, depois de voltar para a casa, fecha o drama que é ser mulher num contexto em que é imposto a ela a identidade de um sexo frágil: “- Preciso de sapatos novos! os meus fazem muito barulho, uma mulher não pode andar com salto de madeira, chama muito atenção!” (LISPECTOR, 2009, p. 93)

Nas crônicas analisadas, chama-nos atenção o predomínio de um discurso que enfatiza a necessidade da mulher estar sempre ornamentada. Observa-se, nesse sentido, um discurso, o qual redimensiona a mulher à qualidade de objeto sexual. Pensando por exemplo nas projeções argumentativas do verbo "vestir", subtende-se um vestir-se para alguém, que no caso das crônicas sempre é preenchido pelo termo "homem, marido".

As crônicas são relatos pessoais de uma mulher ficcional experiente, que tem por finalidade orientar as suas leitoras em suas condutas sociais como mulher, no sentido de impor um comportamento normativo. Diferentemente dos contos que localizam essas questões, mas com a finalidade de estilhaça-las, as crônicas são despreocupadas de um teor reflexivo e são construídas discursivamente pela dicotomia homem-mulher, no qual este último sempre aparece condicionada e vivendo em função do primeiro. O fato apontado é verificável, por exemplo, nas crônicas "A verdadeira elegância", "As roupas e os tipos", "Inutilidade", "O que é ser 'sex-appeal”, entre várias outras.

Em "O búfalo", encontramos uma representação outra acerca da figura fe- 
dicional. Narra-se a história de uma mulher, que durante um passeio no zoológico, misturada aos bichos, revela o sentimento de ódio que nutre por um homem que não a amava: "'Eu te odeio', disse ela para um homem cujo crime único era o de não a amar" (LISPECTOR, 2009, p. 127). Diferente das duas mulheres dos contos supracitados, essa aparece como representação do discurso o qual descreve a mulher como aquela que sofre nos laços afetivo. Mas a personagem protagonista de "O búfalo" rompe com esse paradigma, pois o que sente é uma força violenta para odiar o homem que não a ama.

Por fim, para finalizar este trabalho destacamos, no meio das inúmera crônicas enfeixadas em Correio feminino (2006), as quais apenas reafirmam a construção de identidade normativa sobre a mulher, destacamos a crônica "Mulher botão de rosa", exceção, pois nela está contida uma crítica social aos modelos tradicionais de mulher enunciada num espaço, cujo objetivo não visava a apresenta o tônus social dos contos apontados por nós:

Pois no século XVIII, caíram artificialmente, perucas, mulheres fatais. Surgiu o ideal da mulher botão de rosa. Na palidez de um rosto, os lábios eram mal e mal rosados, se rosados eram. Os cabelos enrolavam-se em longos cachos. Era o estilo da era vitoriana: a simplicidade virginal. $E$ as coisas iam tão bem, aparentemente, que um otimista da época fez comentário: "Parece-me impossível que o 'rouge" volte jamais às faces de um rosto feminino."

O comentarista não sabia o que é moda. Não lhe ocorrera que as mulheres se haviam tornado tão "virginais" porque este era o ideal moral e convencional dos homens. Que, evidentemente, mudaram em seguida. (LISPECTOR, 2006, p. 112)

Portanto, nos três contos analisados está descrito o itinerário banal de personagens mulheres, mas que, por trás do cotidiano narrado, escondem-se as manifestações críticas que essas narrativas fazem contra os discursos que envolve a figura tradicional da mulher. Esses textos, contos e crônicas, são, ao nosso ver, constituintes de um mesmo corpo. Aproximam-se à imagem metafórica de um ímã, o qual contém na sua estrutura corpórea duas polaridades: uma positiva, que refuta e outra negativa, que absorve. Nesse sentido, os contos são representados pela polaridade positiva e as crônicas, o polo negativo, que absorve os discursos normativos. Contudo, apesar dessa dialética das polaridades, eles espelham a problemática aqui abordada, a qual se repete mesmo após vários períodos de reivindicação por igualdade de gênero.

\section{CONSIDERAÇÕES FINAIS}

A travessia dos contos para as crônicas escritas em colunas femininas não se resume a uma simples questão de gênero textual, mas do que isso, acentua-se, na passagem, a mudança discursiva em torno de uma mesma temática: a condição social da mulher. $\mathrm{O}$ espaço de produção é um dos fatores de cisão/tensão entre esses textos, pois existem contextos específicos operando e incidindo sobre a produção do texto da autora modernista.

Os contos tende a entrelaçar a função estética do texto à uma funcionalidade da narrativa, a qual possibilita uma leitura vinculada a uma crítica social. Nas crônicas, predomina, como tentamos demostrar, uma temática das "futilidades" do cotidiano da mulher, ligados à visão tradicional de mulher. Contudo, apesar desses desdobramentos, tentamos ler essas crônicas, a partir de sua plasticidade textual, como arquivos capazes de provocar um exercício reflexivo sobre a condição histórica da mulher, a qual sempre teve uma identidade e um papel social imposto pelo outro, sem a presença de sua própria voz.

Por fim, neste breve trabalho comparativo - considerando que apresen- VOL. 14 | N.2 | DEZ. 2017 
tamos apenas um recorte de uma temática que é muito mais ampla — verificamos como está configurada a representação e a identidade feminina em gêneros distintos da obra de Clarice Lispector.

\section{REFERÊNCIAS}

ARISTÓTELES. Poética. In: BRANDÃO, Roberto (Org.): A poética clássica. São Paulo: Cultrix, 2005.

BOSI, Alfredo. História Concisa da Literatura Brasileira. 43. ed. São Paulo: Cultrix, 2006

BORDINI, Maria da Glória. Estudos Culturais e Estudos Literários. Letras de Hoje. Porto Alegre, v. 41, n. 3, p. 11-22, set. 2006

BAKHTIN, Mikhail. Estética da Criação Verbal. Trad. Paulo Bezerra. 2. ed. São Paulo: Martins Fontes, 1997.

BENJAMIN, Walter. A modernidade e os modernos. Trad. Heidrun Krieger et al. 2. ed. Rio de Janeiro: Tempo Brasileiro, 2000.

BHABHA, Homi. O local da cultura. Trad. Myriam Ávila et al. Belo Horizonte: Ed. UFMG, 1998.

BUTLER, Judith. Problemas de Gênero: feminismo e subversão da identidade. Trad. Renato Aguiar. Rio de Janeiro: Civilização Brasileira, 2003.

CANDIDO, Antonio. Literatura e sociedade: estudos de teoria e história literária. São Paulo: T. A. Queiroz, 2000.

. No raiar de Clarice Lispector. In: Vários escritos. São Paulo: Livraria Duas Cidades. 1970.

COUTINHO, Eduardo F.; CARVALHAL, Tania F. (Orgs.). Literatura Comparada: textos fundadores. Rio de Janeiro: Rocco, 1994.

FOUCAULT, Michel. Microfísica do poder. Trad. Roberto Machado. 7. ed. Rio de Janeiro: Graal, 1979.

A arqueologia do saber. Trad. Luiz Felipe Baeta. 8 ed. Rio de Janeiro: Forense Universitária, 2014.

GÓIS, Edma Cristina de. $O$ dever da faceirice: corpo feminino no colunismo e na ficção de Clarice Lispector. In: GOMES, André Luiz (org.). Clarice em cena: 30 anos depois. Seminário Internacional. Universidade de Brasília, 2008.

GOTLIB, Nádia. Clarice uma vida que se conta. São Paulo: Edusp, 2011.

HALL, Stuart. A identidade cultural na pós-modernidade. Trad. Tomaz Tadeu da Silva. 11. ed. Rio de Janeiro: DPeA, 2011.

ISER, Wolfgang. O ato da leitura.Trad. Johannes Kretschmer. São Paulo: Ed. 34, 1996. 2 v.

JAUSS. Hans Robert. A história da literatura como provocação à teoria literária. 
LISPECTOR, Clarice. A paixão segundo G.H. Ed. crítica de Benedito Nunes, Archives: Brasília, DF: CNPq, 1988.

. A paixão segundo G.H. Rio de Janeiro: Rocco, 2009

. Correio feminino. Rio de Janeiro: Rocco, 2006.

. Laços de Família. Rio de Janeiro: Rocco, 2009.

LIMA, Luiz Costa. Documento e ficção. In: Sociedade e discurso ficcional. Rio de Janeiro: Guanabara, 1986.

NUNES, Aparecida Maria. Clarice Lispector: jornalista feminina. In: LISPECTOR, Clarice. Correio feminino. Rio de Janeiro: Rocco, 2006a.

NUNES, Benedito. A clave do poético. São Paulo: Companhia das Letras, 2009b. 1989.

O drama da linguagem: uma leitura de Clarice Lispector. São Paulo: Ática,

REMAK, Henry H. H. Literatura compara: definição e função. In: COUTINHO, Eduardo F.; CARVALHAL, Tania F. (org.). Literatura Comparada: textos fundadores. Rio de Janeiro: Rocco, 1994.

SOUZA, Eneida. Crítica Cult. Belo Horizonte: Ed. UFMG, 2007

VIEIRA, Telma Maria. Clarice Lispector: uma leitura instigante. 2. ed. São Paulo: Annablume, 2004. 